\title{
Review of Numbers and the Making of Us: Counting and the Course of Human Cultures by Caleb Everett
}

\author{
Geoffrey B. Saxe \\ University of California, Berkeley, CA, USA
}

Numerical representations are woven into the activity of our daily lives. When we press the digits on our phone to make a call, or solve an arithmetic problem, or interpret a graph, we think with and through representations for number. In his book, Numbers and the Making of Us, Caleb Everett, a cognitive linguist by training, offers a broad inquiry into the roots of our numerical thinking, pulling together research from archeology, cultural anthropology, linguistics, cognitive neuroscience, and developmental psychology. He organizes the inquiry by way of a principal argument: Numbers, he argues, are a human invention, and in our use and elaboration of this invention, we have transformed and continue to transform our worlds and our own thinking.

In part I of his three-part book, Everett sketches representations for number that cultural groups have invented. He reviews representations in communities of today as well as those of ancient and prehistoric times. Of particular interest for Everett is the striking diversity in the forms and functions of number. He considers ancient paleolithic artifacts with tally marks, such as an antler with humanly inscribed notches in North America, or tally marks in cave paintings, and he draws his examples from geographically separated regions in Central America,

karger@karger.com

(C) 2020 S. Karger AG, Basel

www.karger.com/hde

Karger!
South America, and Africa. He speculates that tally marks, whether on antlers or in cave paintings, were invented to record regularities of our worlds, like the passage of time. Everett also reviews the historic emergence of diverse conventional systems of numerical representation, including the place value system of the Ancient Mayans, the quipu system of knots of the Incas, and the cuneiform records of ancient Mesopotamia. Moving on to contemporary life, Everett describes the striking variation among modern number systems, pointing to living groups like the Munduruku who have words to convey representations for 1 and 2 but only imprecise reference to greater quantities. Overall, he argues that the representational forms that humans have invented figure into the construction of the varied cultural/material worlds of daily life.

In part II, Everett turns to what we know about and can learn from numerical cognition in three different kinds of populations: cultural/linguistic groups that use very limited number systems (like the numerically limited systems of the Munduruku), nonhuman primates and other species, and human infants/young children. Through his review, he shows that each of these groups can often discriminate between one, two, and three elements, but dis- 
criminations involving quantities greater than three are often inexact. He uses findings from these populations to support the argument that, through evolutionary history, humans are natively endowed with limited but key capabilities to discriminate small quantities, and hence we find these capabilities in nonhuman species, human infants, and cultural groups with limited number systems. For larger quantities, individuals need to rely on the invention of culturally elaborated counting systems, and hence we find such capabilities only in older children and adults in human communities with elaborated representational systems for number.

In part III, Everett reflects on the origins of numbers and arithmetic in human communities. He elaborates on his ideas that quantities exist in the physical world, but numbers do not exist neither in the material world nor are they native parts of our intellect. Indeed, for Everett, numbers are "unnatural." To dig deeper into the origins of number, Everett draws upon the work of notable scholars such as cognitive linguists George Lakoff and Raphael Nuñez (Lakoff \& Núñez, 2000). Everett argues that, through the use of cultural-linguistic devices such as metaphor and other tropes like fictive motion, individuals concretize fundamental but abstract categories of knowledge. For example, he argues, an abstract category like time is rendered concretized and quantifiable through spatial metaphors with the future being "in front of" and the past being "in back of." Such metaphors, Everett points out, may differ across human communities. For instance, for the Aymara, the future is "in back of" (that which cannot be seen) and the past is "in front of" (that which can be seen). Everett's objective is to provide a way to understand how humans come to understand number, but also provide a window into the emergence of crosscultural differences in patterns of thought, a version of linguistic relativity to which Everett subscribes.
As one might expect when reading an ambitious treatment of fewer than 300 pages, there are omissions in Everett's book, and some omissions may be striking to readers of Human Development. Everett's argument that number is a human invention echoes Piaget's seminal theory and research on the origins of cardinal and ordinal number as well as Piaget's critiques of nativist and empiricist accounts of the origins of number (Piaget, 1952), but Everett makes no reference to Piaget's core argumentation and the way it differs from his own. Everett's argument that the emergence of higher cognitive functions like number has roots in culture-specific linguistic systems that children reconstruct to organize their worlds and themselves echoes Vygotsky's seminal developmental treatment (Vygotsky, 1986), but Everett does not come to terms with the way his arguments may be in concert with or clash with Vygotsky's, or perspectives seeded by Vygotsky's writings. Finally, Everett's argument that numbers come into being through individuals' use of cultural-specific linguistic forms echoes aspects of Werner and Kaplan's (1963) analysis of schematizing activity in symbol formation, a process whereby culturally elaborated representational vehicles take on personal meaning for individuals, but there is no effort to engage Werner and Kaplan's important developmental account.

Despite the omission of key developmental scholarship, I found Everett's book to be a well-written, crossdisciplinary account of a fascinating knowledge domain. Of particular interest in my read was Everett's focus on the rootedness of human understanding in both the constructive activities of individuals and the cultural histories with which they participate. In these activities, individuals at once reproduce and alter representational systems for number, a complex historical-developmental perspective that I have elaborated in work of my own (Saxe, 2012).

\section{References}

Everett, C. (2017). Numbers and the making of us: Counting and the course of human cultures. Cambridge, MA: Harvard University Press.

Lakoff, G., \& Núñez, R. (2000). Where mathematics comes from. New York, NY: Basic Books.

Piaget, J. (1952). The child's conception of number. New York, NY: Norton.
Saxe, G. B. (2012). Cultural development of mathematical ideas: Papua New Guinea studies. Cambridge, UK: Cambridge University Press. https://doi.org/10.1017/CBO9781139045360

Vygotsky, L. S. (1986). Thought and language. Cambridge, MA: MIT Press.

Werner, H., \& Kaplan, B. (1963). Symbol formation: An organismic-developmental approach to language and the expression of thought. New York, NY: Wiley. 